\title{
The Association Between Vaginal Candidiasis and Health- promoting Lifestyle in Iranian Women: A Cross-sectional Study
}

\author{
${\text { Parvin } \text { Azhrak }^{1} \text {, Mahin Kamalifard }}^{2}$, Mojgan Mirghafourvand ${ }^{2}$, Soleiman Khedri ${ }^{3}$, Shirin Hasanpour ${ }^{*}(\mathbb{D}$
}

\begin{abstract}
Objectives: Vulvovaginal candidiasis is the second most common gynecological infection in the world that can bring about unfavorable consequences for the health and life of the women of reproductive age. Accordingly, the purpose of this study was to determine the prevalence of vulvovaginal candidiasis and its relationship with the health-promoting lifestyle in Boukan, Iran. Materials and Methods: This cross-sectional study was conducted with the participation of 320 married women aged 15-49 years who referred to all health centers of Boukan. The subjects were selected using a convenience sampling technique from October 2018 to March 2019. Written informed consent was obtained from the participants who were then asked to complete a demographic questionnaire and the Health Promoting Lifestyle Profile-II (HPLP-II). Finally, the data were analyzed in SPSS, version 24.

Results: A total of 124 women (38.8\%) had vulvovaginal candidiasis, and the total mean (standard deviation) score of healthpromoting lifestyle was $2.4(0.2)$ from the possible range of 1-4. None of the demographic characteristics and vulvovaginal candidiasis were significantly related based on the results $(P<0.05)$. The highest $(2.8 \pm 0.3)$ and lowest $(1.6 \pm 0.4)$ mean scores belonged to "nutrition" and "physical activity" subdomains, respectively. In addition, no statistically significant relationship was found between vulvovaginal candidiasis and the total mean score of health-promoting lifestyle and its subdomains $(P>0.05)$.

Conclusions: In general, more than one-third of the participants had vulvovaginal candidiasis. Eventually, the infection had no statistically significant relationship with any of the characteristics of demographic information and health-promoting lifestyle. Keywords: Vulvovaginal candidiasis, Healthy lifestyle, Women health
\end{abstract}

\section{Introduction}

Vulvovaginitis is considered a common cause of women's visits to health centers, accounting for at least 10 million women a year developing infectious, noninfectious, or chronic vulvovaginitis (1). In addition, vulvovaginal candidiasis (VVC) is the second cause of vulvovaginitis after bacterial vaginosis which is clinically diagnosed in around $11.6-17 \%$ of cases (2). The prevalence of VVC is reported at $20-23 \%$ in Iran (3). Further, nearly $3 / 4$ of women experience VVC at least once in their lifetime and approximately $40-50 \%$ of them may later redevelop the infection, and finally, 5-7\% of them develop recurrent VVC (4).

The most general symptoms of VVC include dysuria, itching, hyperemia, irritation, cottage cheese discharge, painful sexual intercourse, abnormal vaginal discharge, and vulvovaginal erythema which occasionally affect the internal parts of the groin (5). Furthermore, the major risk factors of developing VVC are genetic factors, pregnancy, uncontrolled diabetes mellitus, hormone therapy, birth control pills, corticosteroids, intrauterine device, frequent sexual intercourse, high consumption of sweet foods, human immunodeficiency virus infection, frequent antibiotics use, and tight underwear (6).

Numerous pharmaceutical products are used for treating candidiasis with several reported side effects (7-9). Frequent affliction, high costs, sexual problems and dissatisfaction, and infertility are the unfavorable outcomes of candidiasis infection (3).

Therefore, it seems that candidiasis infection can be partly avoided through a healthy lifestyle and hygiene (10). Lifestyle is one's general way of living and behavioral patterns in relation to the type of nutrition, nutritional habits, leisure time, smoking, physical activity, and the use of healthcare services (11-13). Moreover, healthpromoting behaviors are the ones that enable people to enhance their control over their own health, ultimately leading to improved personal and community health (14).

Women are the health hub of the family and the major role models for teaching and promoting a healthy lifestyle for the next generation. Given the increased prevalence of candidiasis among women and the significance of its impact on all aspects of their life, lifestyle recognition and assessment helps the health staff of a community 
Key Messages

- Vaginal candidiasis has adverse effects on the health, quality of life and economy of affected women.

$\checkmark$ Lifestyle modification reduces the prevalence of vaginal candidiasis and promotes women's health.

to organize their activities toward promoting health behaviors and improved lifestyle.

Therefore, the present study aimed to determine the prevalence of VVC and its relationship with healthpromoting lifestyle in Boukan.

\section{Methods and Materials}

Study Design and Participants

This cross-sectional, descriptive-analytic study was carried out on 320 married women who referred to the health centers of Boukan.

The inclusion criteria were being married and having 15-49 years of age. On the other hand, women were excluded from the study if they were pregnant, suffered from diabetes mellitus, had recently taken antibiotics, and took immunosuppressants.

\section{Sample Size}

The sample size was calculated based on the study by Sehati et al, considering a $25.5 \%$ prevalence rate of candidiasis infection, $\alpha=0.05$, and a 0.05 precision rate, and the final sample size was 320 taking a $10 \%$ attrition rate (15).

\section{Sampling}

The ethics code (IR.TBZMED.REC.1397.279) was obtained from the Ethics Committee of Tabriz University of Medical Sciences, and the subjects were selected by means of a convenience sampling method. Boukan has 9 health centers and 7 health stations, and sampling was performed in all these centers and stations. The existing files in each center and station were reviewed and those meeting the inclusion criteria were selected proportionate to the defined ratio for the centers and stations. Additionally, phone calls were made to the subjects, and they were invited to meet at a specific time and date after briefly describing the research objective. On their attendance, the research goals and methods were completely explained, and written informed consent was obtained from those who intended to participate in this study. Then, they completed the demographic questionnaire and the Health Promoting Lifestyle Profile-II (HPLP-II) through an interview and underwent a genital examination by the researcher.

During the genital examination and using a sterile cotton swab, specimens were taken from the vaginal discharges of the posterior fornix and the lateral walls of the vagina. The swab was smeared on a slide together with $50 \mu \mathrm{L}$ of a $10 \%$ potassium hydroxide solution (Merck Company) and examined under a Zeiss microscope using a $\times 40$ objective. If germinated yeasts were observed, the specimen was considered positive for candidiasis infection.

\section{Data Collection Tools}

The data were gathered using a demographic questionnaire and the HPLP-II.

Demographic Questionnaire: It measures two areas of demographic and obstetric information. The questionnaire was validated by means of the face and content validity by presenting it to 10 faculty members and revised according to their opinions.

HPLP-II: It was first developed by Walker et al in 1987 in order to assess health-promoting behaviors (16). The validity of the Persian version was examined by Mohammadi Zeidi et al on a sample of 466 women who were selected through a convenience sampling technique referring to 10 health centers of Qazvin (17). Individual scores for separate dimensions and a total score were obtained accordingly. The questionnaire revolves around six behavioral dimensions including nutrition (9 items), physical activity (8 items), health responsibility (9 items), stress management (8 items), interpersonal relationships (9 items), and spiritual growth (9 items). In addition, the statements are all positive and scored on a four-point Likert-type scale (i.e., never, sometimes, often, and always in the score range of 1-4). Individual item scores and a total score were calculated based on the obtained data.

Further, the reliability of the HPLP-II was evaluated with 20 women using a test-retest method with a twoweek interval through assessing internal consistency and intra-correlation coefficient. Finally, the Cronbach's alpha coefficient and intraclass correlation were computed as 0.808 and 0.963 , respectively.

\section{Data Analysis}

Descriptive statistics including absolute and relative frequency distribution, central tendency, and dispersion (i.e., mean and standard deviation) were used to describe the demographic information, health-promoting behaviors, and the prevalence of candidiasis. Furthermore, the normality of the quantitative data was evaluated by means of skewedness and kurtosis tests. Moreover, an independent t-test was applied to identify the relationship between candidiasis vaginitis and health-promoting lifestyle and its subdomains. Then, the relationship between demographic information and candidiasis vaginitis was assessed using Fisher exact and chi-square tests. Eventually, data were analyzed in SPSS, version 24, and $P<0.05$ was considered statistically significant.

\section{Results}

The analysis of the data showed that about half of the participants (46.9\%) were in the age group of 30-40. Other demographic data are shown in Table 1.

The prevalence of candidiasis vaginitis was $38.8 \%$ (Table 
2 ), and the total mean (SD) score of the health-promoting lifestyle was $2.4(0.2)$ from the possible range of 1-4. Additionally, the highest $(2.8 \pm 0.3)$ and lowest (1.6 \pm 0.4$)$ mean scores were related to the subdomains of "nutrition" and "physical activity", respectively (Table 3 ).

The two-variable independent t-test demonstrated no statistically significant relationship between the prevalence of candidiasis and the total mean score of health-promoting lifestyle and its subdomains (Table 4).

Finally, none of the demographic characteristics and candidiasis was found to be significantly related in Fisher exact and chi-square tests.

\section{Discussion}

The present study attempted to estimate the prevalence of VVC and its relationship with health-promoting lifestyle in Boukan. Vaginitis is regarded as one of the most common factors affecting women's health and is associated with complications that affect women's quality of life. More than one-third (38.8\%) of women had candidiasis vaginitis. In their study on 80 women in Taleshin regarding identifying candida species using mycological and molecular methods, Arefi Lisar et al reported a 25\% prevalence rate for candidiasis infection (18), which is less than the prevalence reported in the present study. In another study, Molazade and Khanjani reported a 31.29\% prevalence among 704 women in Kerman (19), which is relatively consistent with our results. Similarly, Kiasat et al examined 493 women of 15-64 years of age in Ahvaz and reported a $39.76 \%$ prevalence rate (7), showing a relative agreement with the findings of the present study. Different climatic conditions and humidity may be the reasons for varying prevalence rates of candidiasis vaginitis in warm and humid regions as opposed to dry regions and thus further studies are needed in this context.

The total mean score of health-promoting lifestyle was 2.4 in the present study. In addition, the highest and lowest mean scores were related to "nutrition" and "physical activity" subdomains, respectively. In a study by Mirghafourvand et al on 1359 women of reproductive age, the highest and lowest scores of health-promoting behaviors belonged to "interpersonal relationships" and "physical activity", respectively (8), which corroborates with the results of the present study in terms of the "physical activity" score. In another study by Malakouti et al, the highest and lowest mean scores were related to "nutrition" and "physical activity", respectively (9), which is completely in line with our results. Sadeghi also showed that of the lifestyle dimensions, "physical activity" had the lowest score while "spiritual growth" had the highest score (20), which is rather consistent with the findings of the present study in this regard. The lowest score in the above-mentioned studies is related to "physical activity", suggesting the lack of knowledge and education about the importance of the issue whereas the highest score varies across the studies which are probably due to the cultural
Table 1. Demographic, Obstetric, and Health Information of Participants $(n=320)$

\begin{tabular}{|c|c|}
\hline Characteristics & Number (\%) \\
\hline \multicolumn{2}{|l|}{ Age } \\
\hline$<30$ & $104(32.5)$ \\
\hline $30-40$ & 150 (46.9) \\
\hline$>40$ & $66(20.6)$ \\
\hline \multicolumn{2}{|l|}{ Education } \\
\hline Elementary & $142(44.4)$ \\
\hline Middle school & 79 (24.7) \\
\hline High school & $47(14.7)$ \\
\hline Diploma & $32(10.1)$ \\
\hline Academic & $20(6.3)$ \\
\hline \multicolumn{2}{|l|}{ Women's job } \\
\hline Housewife & 214 (66.9) \\
\hline Outside-home employed & $53(16.6)$ \\
\hline Work-at-home employed & $53(16.6)$ \\
\hline \multicolumn{2}{|l|}{ Number of children } \\
\hline 0 & $44(13.8)$ \\
\hline 1 & $90(28.1)$ \\
\hline 2 & 102 (31.9) \\
\hline 3 and more & $106(33.1)$ \\
\hline \multicolumn{2}{|l|}{ Type of delivery } \\
\hline No delivery & $45(14.1)$ \\
\hline Vaginal & $200(62.5)$ \\
\hline C-section & $56(17.5)$ \\
\hline Both & $19(5.9)$ \\
\hline \multicolumn{2}{|l|}{ Smoking } \\
\hline Yes & $0(0)$ \\
\hline No & $320(100)$ \\
\hline \multicolumn{2}{|l|}{ Hookah } \\
\hline Yes & $0(0)$ \\
\hline No & $320(100)$ \\
\hline \multicolumn{2}{|l|}{ Satisfaction with life } \\
\hline Satisfied & $252(78.8)$ \\
\hline Unsatisfied & $20(6.3)$ \\
\hline No opinion & $48(15.0)$ \\
\hline \multicolumn{2}{|l|}{ Monthly income adequacy for living } \\
\hline Enough and more & $288(90.0)$ \\
\hline Less than enough & $32(10.1)$ \\
\hline Current OCP use & $16(5.0)$ \\
\hline \multicolumn{2}{|l|}{ Duration of LD use } \\
\hline$>10$ years & $3(15.0)$ \\
\hline $5-10$ years & $1(5.0)$ \\
\hline$<5$ years & $11(55.0)$ \\
\hline Recently & $1(5.0)$ \\
\hline Vaginal douching & $169(52.8)$ \\
\hline Nylon underwear & $90(28.1)$ \\
\hline Wipe the genitals dry after washing & $195(60.9)$ \\
\hline
\end{tabular}


Table 2. Prevalence of Candidiasis Among Participants ( $n=320$ )

\begin{tabular}{lc}
\hline Candidiasis & Number (\%) \\
\hline Yes & $124(38.8)$ \\
No & $196(61.3)$ \\
\hline
\end{tabular}

Table 3. The State of Health-promoting Lifestyle and its Domain Among the Participants

\begin{tabular}{lccc}
\hline Variable & Mean (SD) & Score Range & Obtained Score \\
\hline $\begin{array}{l}\text { Total score of health- } \\
\text { promoting lifestyle }\end{array}$ & $2.4(0.2)$ & $1-4$ & $1.72-3.30$ \\
$\begin{array}{l}\text { Nutrition } \\
\text { Interpersonal }\end{array}$ & $2.8(0.3)$ & $1-4$ & $1.88-4.00$ \\
relationships & $2.6(0.3)$ & $1-4$ & $1.67-3.56$ \\
Health responsibility & $2.3(0.3)$ & $1-4$ & $1.22-3.33$ \\
Physical activity & $1.6(0.4)$ & $1-4$ & $1.00-3.00$ \\
Stress management & $2.5(0.3)$ & $1-4$ & $1.13-3.50$ \\
Spiritual growth & $2.7(0.3)$ & $1-4$ & $1.44-3.67$ \\
\hline
\end{tabular}

Table 4. The Relationship Between the Candidiasis of Participants and Health-Promoting Lifestyle and its Subdomains

\begin{tabular}{lccc}
\hline \multirow{2}{*}{ Variable } & \multicolumn{2}{c}{ Frequency of Candidiasis } & \multirow{P}{*}{$\begin{array}{c}\boldsymbol{P} \\
\text { Value }\end{array}$} \\
\cline { 2 - 3 } & $\begin{array}{c}\text { Yes } \\
\text { Mean (SD) }\end{array}$ & $\begin{array}{c}\text { No } \\
\text { Mean (SD) }\end{array}$ & \\
\hline $\begin{array}{l}\text { Total score of health- } \\
\text { promoting lifestyle }\end{array}$ & $2.4(0.2)$ & $2.4(0.2)$ & 0.297 \\
Nutrition & $2.8(0.3)$ & $2.9(0.3)$ & 0.638 \\
Interpersonal relationships & $2.5(0.3)$ & $2.6(0.3)$ & 0.209 \\
Health responsibility & $2.3(0.3)$ & $2.3(0.3)$ & 0.715 \\
Physical activity & $1.6(0.4)$ & $1.6(0.4)$ & 0.589 \\
Stress management & $2.5(0.3)$ & $2.5(0.3)$ & 0.441 \\
Spiritual growth & $2.7(0.3)$ & $2.7(0.3)$ & 0.478 \\
\hline
\end{tabular}

Note. SD: standard deviation.

differences of the regions or populations under study.

Based on the results of the present study, no statistically significant relationship was found between candidiasis vaginitis and health-promoting lifestyle and its subdomains. Parsapure et al conducted a study to explore the effects of health training intervention on lifestyle (i.e., nutrition behaviors, physical activity, and mental health) in relation to vaginal health in women of reproductive age with vaginitis in Kermanshah. Their six-month comparison of lifestyle in three dimensions between a control and intervention group revealed no statistically significant relationship (21), which is consistent with our findings.

Further, none of the demographic characteristics had a significant relationship with the prevalence of candidiasis in the current study, which supports the findings of Aali and Tohidi (22). However, Ekuma et al showed a significant relationship between wearing nylon underwear and developing candidiasis infection (23). This is inconsistent with the results of the present study probably due to the fact that in our study, only $28 \%$ of women wore nylon underwear. Likewise, Molazade and Khanjani concluded that there was a significant relationship between candida infection and education, husband's education, husband's job, and natural birth control (19). Furthermore, Parsapour et al argued that the possibility of vaginitis recurrence in women who (or their husband) had low education levels was three times greater than those with higher levels of education, suggesting a relationship between education and vaginitis. The researchers also indicated that people with higher economic status would be less likely to develop the infection while women with more children would be more prone to recurrence (24), which contradicts our results. The possible reason for the difference between the studies could be that most of our participants had low education levels and were housewives. A more accurate comparison would be possible if the number of welleducation women was equal or close to less-education ones.

Moreover, Shahinfar and Noman Pour reported a significant relationship between vaginal infection and education, monthly income, and husband's education while other personal characteristics did not seem to be significantly related to the infection, including job, the number of children, length of the marriage, breastfeeding state, smoking, and number of sexual intercourses in a week (25). This is in agreement with the findings of the present study except for education, monthly income, and husband's education.

One of the limitations of this study was applying a convenience sampling method, thus the results cannot be generalized to all women of reproductive age. The possible insincerity of participants in responding to the questionnaire was another limitation, which was out of the researcher's control and could have affected the results.

Contrarily, the strengths of this research were observing ethical principles, sampling in all health centers and stations of Bukan, using standard questionnaires, and conducting examinations by the researcher herself.

The findings of this study can be used as guidance in planning to promote women's lifestyle. For example, the low score of physical activity in this study demonstrates the importance of physical activity education in women's healthcare programs. Therefore, further interventional studies are suggested in the field of healthy lifestyle promotion for improving women's health.

\section{Conclusions}

More than one-third of the women of reproductive age in Boukan had candidiasis vaginitis. The mean score of the subdomain of "physical activity" was lower compared to the other dimensions of a health-promoting lifestyle. Therefore, educational programs in relation to the importance of physical activity and other healthpromoting behaviors should be taken into account in health centers. 


\section{Authors' Contribution}

$\mathrm{PA}$ and SKh were responsible for data collection, implemented the study and wrote the first draft of the manuscript. ShH and MK contributed to the study design and assisted in the preparation of the final version of the manuscript. MM contributed to data analysis. All the authors read and approved the final version of the manuscript.

\section{Conflict of Interests}

Authors declare that they have no conflict of interests.

\section{Financial Support}

This paper is part of an MSc thesis financially supported by Tabriz University of Medical Sciences, Deputy for Research.

\section{Acknowledgments}

Authors hereby express their gratitude to the Deputy for Research, Tabriz School of Nursing and Midwifery, Student Research Committee of Tabriz University of Medical Education, the staff of the health centers of Boukan, and all participants in this study.

\section{References}

1. Impey L, Child T. Obstetrics and Gynaecology. WileyBlackwell; 2017.

2. Maraki S, Mavromanolaki VE, Stafylaki D, Nioti E, Hamilos G, Kasimati A. Epidemiology and antifungal susceptibility patterns of Candida isolates from Greek women with vulvovaginal candidiasis. Mycoses. 2019;62(8):692-697. doi:10.1111/myc.12946

3. Norouzi S, Salahi Moghadam A, Khoshdel A, Nourifard M, Ayatollahi Mousavi SA. Geographic information system of fungal disease of Iran. Ann Mil Health Sci Res. 2013;11(4):357-374. [Persian].

4. Cassone A, Casadevall A. Recent progress in vaccines against fungal diseases. Curr Opin Microbiol. 2012;15(4):427-433. doi:10.1016/j.mib.2012.04.004

5. Kiasat N, Rezaei-Matehkolaei A, Zarei Mahmoudabadi A, Hamidavi Mohamadpour K, Molavi S, Khoshayand N. Prevalence of vulvovaginal candidiasis in Ahvaz, southwest Iran: a semi-large scale study. Jundishapur J Microbiol. 2019;12(3):e89815. doi:10.5812/jjm.89815

6. Sharma K, Soni G, Morya S, Nahar D. Clinico-mycological profile of vaginitis in reproductive age group in Kota region. Glob J Res Anal. 2019;8(5):205-207.

7. Kiasat N, Rezaei-Matehkolaei A, Mahmoudabadi AZ. Microsatellite typing and antifungal susceptibility of Candida glabrata strains isolated from patients with Candida vaginitis. Front Microbiol. 2019;10:1678. doi: 10.3389/fmicb.2019.01678.

8. Mirghafourvand M, Baheiraei A, Nedjat S, Mohammadi E, Charandabi SM, Majdzadeh R. A population-based study of health-promoting behaviors and their predictors in Iranian women of reproductive age. Health Promot Int. 2015;30(3):586-594. doi:10.1093/heapro/dat086

9. Malakouti J, Sehhati F, Mirghafourvand M, Nahangi R.
Relationship between health promoting lifestyle and perceived stress in pregnant women with preeclampsia. J Caring Sci. 2015;4(2):155-163. doi:10.15171/jcs.2015.016

10. Said SAE, Elbana HM, Salama AM. Education intervention guideline on knowledge and self-care practice for women with vulvovaginities. Int J Stud Nurs. 2019;4(1):73-84. doi:10.20849/ijsn.v4i1.552

11. Grant RW. Alcohol Use, Dietary, and Exercise Behaviors: A Latent Profile Analysis of Young Adult Lifestyle Behaviors [dissertation]. Fayetteville, Arkansas: University of Arkansas; 2019.

12. Hamadeh S, Marquis M, Estepan S. Ten-point vision strategies to offer a menu of options to promote healthy eating and active living in Lebanon: between facts and stories. Clin J Nutr Diet. 2019;2(1);1-9.

13. Beeken RJ, Haviland JS, Taylor C, et al. Smoking, alcohol consumption, diet and physical activity following stoma formation surgery, stoma-related concerns, and desire for lifestyle advice: a United Kingdom survey. BMC Public Health. 2019;19(1):574. doi:10.1186/s12889-019-6913-z

14. Fathnezhad-Kazemi A, Hajian S. Factors influencing the adoption of health promoting behaviors in overweight pregnant women: a qualitative study. BMC Pregnancy Childbirth. 2019;19(1):43. doi:10.1186/s12884-019-2199-5

15. Sehhatie-Shafaie F, Namazi A. Prevalence, risk factors, and clinical findings of candidiasis and trichomoniasis in women supported by selected health centers of Tabriz, Iran. Crescent J Med Biol Sci. 2014;1(4):130-5.

16. Walker SN, Kerr MJ, Pender NJ, Sechrist KR. A Spanish language version of the health-promoting lifestyle profile. Nurs Res. 1990;39(5):268-273.

17. Mohammadi Zeidi I, Pakpour Hajiagha A, Mohammadi Zeidi B. Reliability and validity of Persian version of the health-promoting lifestyle profile. Journal of Mazandaran University of Medical Sciences. 2012;21(1):102-113. [Persian].

18. Arefi Lisar N, Kordbacheh P, Rezaie S, et al. Identification of Candida species by molecular and mycological methods in pregnant women with vulvovaginal candidiasis. Tehran University Medical Journal. 2018;75(12):894-901. [Persian].

19. Molazade P, Khanjani N. The prevalence of infection and antifungal drug susceptibility of Candida vaginitis in women visiting clinics in Kerman in 2013. Journal of Rafsanjan University of Medical Sciences. 2016;14(12):1061-1072. [Persian].

20. Rabieepur S, Sadeghi E. Survey of health-promoting lifestyles and related factors in pregnant women referring to health centers of Urmia in 2015. Tehran-Iran: IRHRC Annual Meeting Reproductive and Infertility Updates; 2015.

21. Parsapure R, Rahimiforushani A, Majlessi F, Montazeri A, Sadeghi R, Garmarudi G. Impact of health-promoting educational intervention on lifestyle (nutrition behaviors, physical activity and mental health) related to vaginal health among reproductive-aged women with vaginitis. Iran Red Crescent Med J. 2016;18(10):e37698. doi:10.5812/ ircmj.37698

22. Aali B, Tohidi A. of Candida vaginits among symptomatic patients in Kerman. The Journal of Qazvin University of Medical Sciences. 2000;4(1):42-48. [Persian]. 
23. Ekuma A, Ikenyi C, Moses A. Candida colonization and genital hygiene habits among women in Uyo, Nigeria. J Res Basic Clin Sci. 2019;1(1):17-22.

24. Parsapour R, Majlessi F, Rahimiforoushani A, Sadeghi R. Determination of factors affecting relapse of vaginitis among reproductive-aged women: an experimental study. Electron Physician. 2017;9(1):3499-3507. doi:10.19082/3499
25. Shahinfar S, Noman Pour B. The relationship between various individual characteristics and common vaginal infections among the women referring to Payambar Azam gynecology clinic in Kerman city [Persian]. Iran J Obstet Gynecol Infertil. 2015;18(148):10-17. doi:10.22038/ ijogi.2015.4508

(C) 2020 The Author(s); This is an open-access article distributed under the terms of the Creative Commons Attribution License (http:// creativecommons.org/licenses/by/4.0), which permits unrestricted use, distribution, and reproduction in any medium, provided the original work is properly cited. 